\title{
Neighborhood Influences on Girls' Obesity Risk Across the Transition to Adolescence
}

WHAT'S KNOWN ON THIS SUBJECT: The built environment may affect weight status by presenting opportunities or barriers for exercise and nutritious eating. Although there is substantial cross-sectional evidence linking neighborhood factors and childhood obesity, causal uncertainty remains, owing to conceptual and methodological challenges.

WHAT THIS STUDY ADDS: This prospective study examined neighborhood influences on obesity during the transition to adolescence, a sensitive period for excess weight gain. Girls living in neighborhoods characterized by physical disorder or increased access to food and service retailers exhibited higher obesity risk.

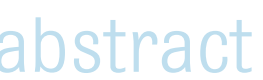

BACKGROUND AND OBJECTIVES: The neighborhoods in which children live, play, and eat provide an environmental context that may influence obesity risk and ameliorate or exacerbate health disparities. The current study examines whether neighborhood characteristics predict obesity in a prospective cohort of girls.

METHODS: Participants were 174 girls (aged 8-10 years at baseline), a subset from the Cohort Study of Young Girls' Nutrition, Environment, and Transitions. Trained observers completed street audits within a 0.25 -mile radius around each girl's residence. Four scales (food and service retail, recreation, walkability, and physical disorder) were created from 40 observed neighborhood features. BMI was calculated from clinically measured height and weight. Obesity was defined as BMl-for-age $\geq 95 \%$. Logistic regression models using generalized estimating equations were used to examine neighborhood influences on obesity risk over 4 years of follow-up, controlling for race/ethnicity, pubertal status, and baseline BMI. Fully adjusted models also controlled for household income, parent education, and a census tract measure of neighborhood socioeconomic status.

RESULTS: A 1-SD increase on the food and service retail scale was associated with a 2.27 (95\% confidence interval, 1.42 to $3.61 ; P<.001$ ) increased odds of being obese. A 1-SD increase in physical disorder was associated with a 2.41 (95\% confidence interval, 1.31 to 4.44; $P=$ .005) increased odds of being obese. Other neighborhood scales were not associated with risk for obesity.

CONCLUSIONS: Neighborhood food and retail environment and physical disorder around a girl's home predict risk for obesity across the transition from late childhood to adolescence. Pediatrics 2014;134:942-949

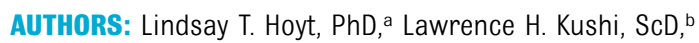
Cindy W. Leung, ScD, MPH, ${ }^{c}$ Dana C. Nickleach, MA, ${ }^{d}$ Nancy Adler, PhD, ${ }^{\text {cee }}$ Barbara A. Laraia, PhD, MPH, ${ }^{f}$ Robert A. Hiatt, $\mathrm{MD}, \mathrm{PhD},{ }^{8}$ and Irene H. Yen, PhD, MPH ${ }^{\mathrm{h}}$

aRobert Wood Johnson Foundation Health and Society Scholar, University of California, San Francisco and Berkeley, California ${ }^{b}$ Division of Research, Kaiser Permanente, Oakland, California; ${ }^{c}$ Center for Health and Community, Departments of ${ }^{e}$ Psychiatry and Pediatrics, ${ }^{g}$ Epidemiology and Biostatistics, and ${ }^{h}$ Medicine, University of California, San Francisco, California; ${ }^{d}$ Winship Cancer Institute, Emory University, Atlanta, Georgia; and ${ }^{f}$ School of Public Health, University of California, Berkeley, California

\section{KEY WORDS}

neighborhood, adolescent development, obesity

\section{ABBREVIATIONS}

$\mathrm{Cl}$-confidence interval

CYGNET—Cohort Study of Young Girls' Nutrition, Environment, and Transitions

KPNC—Kaiser Permanente Northern California

SES- socioeconomic status

Dr Hoyt created the analysis plan, conducted the analysis, and drafted the manuscript; Dr Kushi is the principal investigator of the CYGNET Study, contributed to the design of the ancillary CYGNET Neighborhood Study, and critically reviewed the manuscript; Dr Leung and Ms Nickleach helped to design the study's statistical methodology, calculated the neighborhood scales, conducted preliminary analyses, and critically reviewed the manuscript; Dr Adler is co-Investigator of the ancillary CYGNET Neighborhood Study, contributing to the design and implementation of the street audit data collection, and she critically reviewed the manuscript; Dr Laraia obtained the census variables, derived the Neighborhood Deprivation Index using these measures, and critically reviewed the manuscript; Dr Hiatt is principal investigator of the Coordinating Center for the Breast Cancer and the Environment Research Program that coordinates the 3 study sites, of which CYGNET is 1 , following cohorts of girls as they transition through puberty. Dr Hiatt is also co-Investigator of the CYGNET Neighborhood Study. He contributed to the design of the street audit data collection and critically reviewed the manuscript; Dr Yen is the principal investigator of the ancillary CYGNET Neighborhood Study, she directed the collection of the street audit data, oversaw the calculation of the neighborhood scales, helped with data analysis and interpretation, and contributed to writing and revising the manuscript; and all authors approved the final manuscript as submitted.

www.pediatrics.org/cgi/doi/10.1542/peds.2014-1286

doi:10.1542/peds.2014-1286

Accepted for publication Aug 21, 2014

(Continued on last page) 
The neighborhoods in which children live, play, and eat provide an important environmental context that may influence obesity risk. Although recent reports imply that rising rates of youth obesity have plateaued in the last decade, ${ }^{1-4}$ a new study suggests that the overall trend masks a significant and growing socioeconomic status (SES) disparity in obesity among US adolescents: since 2002, obesity has begun to decline among higher SES youth, but continues to increase among low SES youth. ${ }^{5}$ These findings highlight the pressing need to identify environmental factors that contribute to the high prevalence rates (eg, 17\% of youth aged 12-19 years) and to the increasing SES disparity in adolescent obesity., 6,7

Contextual, poverty-related indicators such as neighborhood deprivation ${ }^{8,9}$ and lower perceived neighborhood safety ${ }^{10,11}$ are positively associated with children's BMl and weight status. Conversely, children living in high-income neighborhoods have greater access to physical activity resources than children in low-income areas. ${ }^{12}$ Additional evidence suggests that built environment features predict children's weight status independent of SES, with the presence of convenience stores and fast-food outlets associated with increased obesity risk and higher BMl, ${ }^{13,14}$ and neighborhood walkability related to reduced obesity risk. ${ }^{15}$ However, other studies have found that direct effects of neighborhood environment on obesity are minimal when sociodemographic factors are taken into account. 16,17

Despite growing interest in environmental influences on health, most research investigating neighborhood characteristics and childhood obesity is cross-sectional, making it difficult to infer causality, and uses commercial or business databases to measure neighborhood elements, which may not capture the quality of youths' most proximal environments. ${ }^{18}$ Additionally, few studies have examined the relationship between neighborhood characteristics and obesity during the transition to adolescence, a developmental period of accelerated growth and physical change second only to infancy. ${ }^{19}$ Adolescent girls gain an average of 24 pounds during puberty, with a peak weight velocity of 18 pounds/year around age 12.5 years..$^{19,20}$ These dynamic changes in body size and shape may evoke a sensitive period for excess weight gain, especially among girls. ${ }^{21-23}$ The current study seeks to address these limitations by investigating whether directly measured neighborhood characteristics predict obesity among early adolescent girls across 4 years of development. We hypothesized that the food environment (eg, presence of fast-food outlets) and neighborhood economic deprivation would increase the risk for obesity, whereas access to recreational resources or neighborhood walkability would be associated with lower risk for obesity. Furthermore, we hypothesized that these neighborhood features within girls' immediate environments would predict obesity risk above and beyond family and neighborhood SES.

\section{METHODS}

\section{Participants and Procedures}

The study sample comprised participants enrolled in the Cohort Study of Young Girls' Nutrition, Environment and Transitions (CYGNET Study). The CYGNET Study is a prospective cohort study examining environmental exposures associated with differences in the age-at-onset of pubertal development, and is funded under the Breast Cancer and Environment Research Program of the National Institute of Environmental Health Sciences and the National Cancer Institute. ${ }^{24}$

In 2005, 444 girls were recruited through the Kaiser Permanente Northern California (KPNC) Infant Cohort File, a database containing information on all live births occurring in KPNC facilities.
Eligibility included being female, age 6 or 7 years at time of recruitment, member of KPNC, resident of Marin County, San Francisco, or selected East Bay Communities at time of recruitment and at birth, and not intending to move from the area in the near future. Girls having a pre-existing medical condition known to influence puberty or a psychiatric condition that could potentially limit study participation were excluded. CYGNET Study participants have been followed with annual clinical visits, during which anthropometric measurements and pubertal stage evaluations were collected by trained clinic staff. ${ }^{25}$ Each visit also included an interview with the primary caregiver about demographic factors, chemical exposures, general health, psychosocial factors, and residential history.

Participants for the current study were a subsample of CYGNET Study participants who were randomly selected to participate in an ancillary study of the built environment $(n=215)$. This study was initiated in the third year of data collection (2007-2008), when the girls were aged 8 to 10 years (hereafter referred to as the baseline visit). Inperson street audits were conducted within girls' residential neighborhoods using a modified version of the St Louis Audit Tool. ${ }^{26}$ Trained street observers were provided a map with a 0.25 -mile circle around each girl's residence, with random selections of every third street segment highlighted. A street segment was defined as the length of the street to the nearest crossroad or major curve, and the number of street segments observed per girl was dependent on the length and density of the streets within each neighborhood. The street observers completed 1 audit form for both sides of each highlighted street segment. An average of 10.6 segments was observed per girl. To ensure accuracy between observers, 
different observers audited 246 duplicate street segments. Thirty discrepancies were found among 16728 audit tool items, yielding a $0.2 \%$ disagreement rate.

The analytical sample for the current study was restricted to girls with neighborhood assessments for their baseline address, ${ }^{*}$ baseline clinical and questionnaire data, and at least 1 year of follow-up data ${ }^{\dagger}(n=174)$. Parental consent and child assent were obtained from all study participants. The Institutional Review Boards at both the University of California, San Francisco and KPNC approved all study procedures.

\section{Measures}

\section{Outcome}

BMI was calculated as the ratio of weight in kilograms over height in meters squared. Weight was measured without shoes or socks, using a calibrated digital Tanita scale TBF 300A and height was measured using a fixed stadiometer. BMI $z$ scores, the number of SD units that the BMI deviates from the mean reference value, were calculated based on age- and gender-specific standards from the Centers for Disease Control and Prevention, with $\mathrm{BMI} \geq 95$ th percentile defined as obese.

\section{Neighborhood Scales}

Neighborhood audit data were averaged across the number of street segments observed per girl, to preserve the unit of observation as the individual. Each mean was dichotomized with the value of 1 if the targeted attribute was visible on any observed street segment and 0 if not visible. To reduce dimensionality of the neighborhood data, a rigorous factor

\footnotetext{
*We had to exclude 10 girls who moved during baseline data collection, as we did not have street audit data for their updated home addresses.

'Seventy-two percent of the sample includes all 4 years of follow-up data from baseline (2007-2008) to final outcomes measured in 2011-2012.
}

analysis was performed on 40 observed neighborhood features. Details on this exploratory factors analysis and the resulting neighborhood scales are explained in a previous publication from our research team. ${ }^{27}$ Four scales were examined in the current study: (1) food and service retail (included chain fastfood restaurant; supermarket; other convenience food restaurant; laundry or dry cleaners; full-service restaurant; coffee shop); (2) recreation (included park; walking or hiking trails; sports/ playing field, basketball courts or tennis courts); (3) walkability (included street shoulders or wide outside lanes; curb bulb out/curb extension; traffic circle/roundabout); and (4) physical disorder (included garbage, litter, or broken glass on sidewalks or streets; graffiti on buildings). A higher score in any of the scales indicated a greater presence of those attributes around each girl's home. Because every scale had a different number of factors and numeric range, each neighborhood scale was standardized (mean $=0 ; S D=1$ ) before analysis.

\section{Neighborhood and Family SES}

The following 8 variables were used to create an empirical summary of neighborhood SES from the 2000 Census: percent of individuals who had income below poverty level; percent of families who had female-headed households with children age $<18$ years and no husband present; percent of households with incomes under $\$ 30$ 000/year; percent of households with public assistance income; percent of people age $\geq 16$ years in civilian labor force who are currently unemployed; percent of males in management; percent of all persons age $\geq 25$ years who had less than a high school degree; and percent of households with $>1$ person per room. Following procedures set out by Messer and colleagues, the authors fit a principal-components analysis to obtain the item loadings, which were used to weigh each census variable's contribution to the first principal component. ${ }^{28}$ The first component $(\alpha=0.93)$ was standardized to create an individual neighborhood SES scale for each girl based on her census tract.

We also assessed 2 measures of family SES: household income and parent/ guardian education level. Caregivers reported annual household income at baseline according to the following categories: $<\$ 25000 ; \$ 25000$ to $\$ 49$ 999; $\$ 50000$ to $\$ 74$ 999; $\$ 75000$ to $\$ 99999$; $\geq \$ 100000$. They also reported the educational attainment for the primary financial provider in the household, which was then collapsed into 5 categories: high school or less; some college or vocational training; associate's degree; bachelor's degree; master's or doctoral degree.

\section{Additional Covariates}

Caregivers also reported each girl's race/ethnicity (non-Hispanic white, African American or black, Hispanic or Latina, and Asian American) and household size (number of people currently living in the child's home) at baseline. Pubertal development was assessed by clinical examination using the widely used scales developed by Tanner and colleagues. ${ }^{29,30}$ The initiation of puberty in girls is coincident with the activation of 2 independent systems: gonadarche and adrenarche. ${ }^{24}$ Specially trained research assistants under the supervision of a pediatric endocrinologist examined youth for Tanner breast stage (a representation of gonadarche in girls) and pubic hair development (a physical manifestation of adrenarche). Girls were categorized as either prepubertal (Tanner stage 1) or pubertal (Tanner stages 2-5) at baseline, for both breast and pubic hair stage. 


\section{Analysis}

Logistic regression models were used to examine the association between neighborhood characteristics at baseline (2007-2008) and the risk for obesity over 4 years of follow-up (through 2011-2012). Analyses were clustered within person using generalized estimating equations to correct for multiple time points per participant (each girl may have up to 4 observations after her baseline measure). The exposures of interest were the 4 neighborhood scales, each of which were examined separately.

Using updated address records (collected as part of each wave of data collection to identify girls who moved over the course of the study), we also replicated analyses excluding observations that occurred after a participant moved, as a robustness check. All statistical analyses were conducted by using SAS 9.4 (SAS Institute Inc, Cary, NC), statistical tests were 2-sided, and significance was determined at $P<.05$.

\section{RESULTS}

Characteristics of the study population at baseline are presented in Table 1. The sample is $20 \%$ African American, 22\% Hispanic/Latina, 12\% Asian, and $46 \%$ non-Hispanic white. Just over half (55\%) of the girls lived in households with at least 1 collegeeducated caregiver. Girls' mean age was 9.3 years $(S D=0.44)$ and most had not yet entered puberty, as indicated by breast (63\% prepubertal) or pubic hair (72\% prepubertal) stage 2 or greater. The average baseline BMI $z$ score was $0.36 \pm 1.07 \mathrm{SD}$ above the national mean, with $14 \%$ of girls classified as obese.

\footnotetext{
${ }^{+}$Participants lived in neighborhoods across the entire San Francisco Bay area, with no 2 participants residing within the same neighborhood block. Therefore, additional clustering within neighborhood was not necessary.
}

TABLE 1 Select Characteristics for CYGNET Study Girls at Baseline, 2007-2008 $(n=174)$

\begin{tabular}{|c|c|c|}
\hline Characteristic & & \\
\hline \multicolumn{3}{|l|}{ Neighborhood scales } \\
\hline Food and service retail & 3.00 & $(2.52)$ \\
\hline Recreation & 1.15 & $(1.42)$ \\
\hline Walkability & 2.65 & $(1.29)$ \\
\hline Physical disorder & 1.75 & $(1.09)$ \\
\hline Number of street segments & 10.58 & $(5.50)$ \\
\hline Neighborhood SES (census tract) & -0.05 & $(2.33)$ \\
\hline Household size & 4.05 & $(0.99)$ \\
\hline \multicolumn{3}{|l|}{ BMI } \\
\hline BMI raw score & 18.20 & $(3.50)$ \\
\hline \multirow[t]{2}{*}{ BMI z score } & 0.36 & $(1.07)$ \\
\hline & $N$ & $\%$ \\
\hline \multicolumn{3}{|l|}{ Tanner breast development ${ }^{a}$} \\
\hline Pre-thelarche (Tanner stage 1) & 107 & 63 \\
\hline Thelarche (Tanner stage 2-5) & 62 & 37 \\
\hline \multicolumn{3}{|l|}{ Tanner pubic hair development ${ }^{\mathrm{b}}$} \\
\hline Pre-pubarche (Tanner stage 1) & 120 & 72 \\
\hline Pubarche (Tanner stage 2-5) & 47 & 28 \\
\hline \multicolumn{3}{|l|}{ Race/ethnicity } \\
\hline White & 80 & 46 \\
\hline African American & 34 & 20 \\
\hline Latino & 39 & 22 \\
\hline Asian & 21 & 12 \\
\hline \multicolumn{3}{|c|}{ Highest education of primary financial provider in household } \\
\hline High school degree or less & 32 & 18 \\
\hline Some college/vocational school & 31 & 18 \\
\hline Associate's degree & 15 & 9 \\
\hline College degree & 52 & 30 \\
\hline Master's or doctorate degree & 44 & 25 \\
\hline \multicolumn{3}{|l|}{ Household income $^{c}$} \\
\hline$<\$ 25000$ & 7 & 4 \\
\hline$\$ 25000$ to $\$ 49999$ & 26 & 15 \\
\hline$\$ 50000$ to $\$ 74999$ & 25 & 14 \\
\hline$\$ 75000$ to $\$ 99999$ & 36 & 21 \\
\hline$\geq \$ 100000$ & 79 & 46 \\
\hline
\end{tabular}

a Missing data on 5 cases.

${ }^{b}$ Missing data on 7 cases.

${ }^{\mathrm{c}}$ Missing data on 1 case.

The first set of models in Table 2 presents the results of logistic regression analyses for obesity, controlling for baseline BMI $z$ score, stage of pubertal development, race/ ethnicity, total number of street segments observed per girl, and the year of the outcome measure. Both the food and service retail scale (odds ratio $=2.40$; $95 \%$ confidence interval [Cl], 1.44 to 4.02 ; $P<.001)$ and physical disorder scale (odds ratio $=2.53$; $95 \% \mathrm{Cl}, 1.28$ to 5.01 ; $P=.008)$ predicted increased odds of obesity over the 4-year transition from late childhood to early adolescence. The second set of models also controlled for family SES (parents' education, household income, household size) and neighborhood SES (based on census tract). $\S$ In these fully adjusted models, a 1-SD increase on the food and service retail scale was associated with 2.27-fold higher odds of being obese in adolescence $(95 \% \mathrm{Cl}$, 1.42 to $3.61 ; P<.001)$. Similarly, a $1-S D$ increase in physical disorder was associated with 2.41-fold higher odds of

\footnotetext{
§Parents' educational level was significantly inversely associated with obesity risk (reported in the Supplemental Tables), but there was no significant effect for either household income or neighborhood SES.
} 
TABLE 2 Effect of Neighborhood Scales on the Likelihood of Development of Obesity in the CYGNET Study, 2007-2012 ( $n=601$ Observations From 174 Girls)

\begin{tabular}{|c|c|c|c|c|}
\hline \multirow[t]{2}{*}{ Neighborhood scale } & \multicolumn{2}{|c|}{ Model $1^{\mathrm{a}}$} & \multicolumn{2}{|c|}{ Model $2^{b}$} \\
\hline & OR & $95 \% \mathrm{Cl}$ & OR & $95 \% \mathrm{Cl}$ \\
\hline Food and service retail & $2.40^{\star \star \star}$ & 1.44 to 4.02 & $2.27^{\star \star \star}$ & 1.42 to 3.61 \\
\hline Recreation & 0.97 & 0.55 to 1.69 & 0.84 & 0.50 to 1.40 \\
\hline Walkability & 1.02 & 0.63 to 1.67 & 0.85 & 0.53 to 1.36 \\
\hline Physical disorder & $2.53^{\star \star}$ & 1.28 to 5.01 & $2.41^{\star \star}$ & 1.31 to 4.44 \\
\hline
\end{tabular}

*** $P<.001 .{ }^{* *} P<.01 .0 \mathrm{R}$, odds ratio.

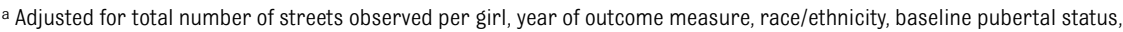
and baseline BMI.

${ }^{b}$ Adjusted for all covariates in Model 1 and also controlling for baseline measures of neighborhood (census tract) SES, parents' highest level of education, household income, and household size. being obese in adolescence $(95 \% \mathrm{Cl}$, 1.31 to $4.44 ; P<.005)$. Neither walkability nor recreation scales predicted obesity risk.

Table 3 presents the same analyses in which observations occurring after a participant moved ( $n=59$ observations from 27 girls) were excluded. We found a very similar pattern of results, with both food and service retail and physical disorder associated with more than twice the odds of becoming obese across the transition to adolescence.

\section{DISCUSSION}

Although changes in body size, shape, and composition during adolescence are expected and healthy, previous research suggests that these rapid and dynamic processes initiate a vulnerable period for excess weight gain. ${ }^{21,22}$ 0bese adolescents are more likely to become obese adults ${ }^{31,32}$ and obesity during adolescence predicts adult morbidity, independent of the effects of adolescent weight on adult weight. 33 The current study examined whether characteristics of the neighborhood environment are associated with the progression of obesity in girls across the transition from late childhood to early adolescence. We found that living in a neighborhood with a higher density of food and service shops, or characterized by physical disorder, was associated with increased probability of progressing toward obesity in adolescence. These effects were independent of various factors, including household income and neighborhood SES.

A substantial body of cross-sectional evidence suggests that the consumption of energy-dense foods sold by convenience and fast-food retailers is likely to be important in the etiology of obesity. ${ }^{13,14,34-37}$ Exposure to these retail options in the immediate
TABLE 3 Effect of Neighborhood Scales on the Likelihood of Developing Obesity for Participants Who Did Not Change Residence Over the Study Period in the CYGNET Study, 2007-2012 ( $n=542$ Observations From 147 Girls)

\begin{tabular}{|c|c|c|c|c|}
\hline \multirow[t]{2}{*}{ Neighborhood scale } & \multicolumn{2}{|c|}{ Model $1^{a}$} & \multicolumn{2}{|c|}{ Model $2^{b}$} \\
\hline & Adjusted OR & $95 \% \mathrm{Cl}$ & Adjusted OR & $95 \% \mathrm{Cl}$ \\
\hline Food and service retail & $2.24^{\star \star}$ & 1.31 to 3.84 & $2.24^{\star \star}$ & 1.31 to 3.84 \\
\hline Recreation & 1.01 & 0.56 to 1.82 & 0.72 & 0.38 to 1.35 \\
\hline Walkability & 1.11 & 0.66 to 1.86 & 0.92 & 0.54 to 1.57 \\
\hline Physical disorder & $2.30^{*}$ & 1.14 to 4.63 & $2.29 *$ & 1.09 to 4.82 \\
\hline
\end{tabular}

${ }^{\star *} P<.01 .{ }^{*} P<.05 .0 \mathrm{R}$, odds ratio.

a Adjusted for total number of streets observed per girl, year of outcome measure, race/ethnicity, baseline pubertal status, and baseline BMI.

b Adjusted for all covariates in Model 1 and also controlling for baseline measures of neighborhood (census tract) SES, parents' highest level of education, household income, and household size. environment may be an especially important predictor of unhealthy weight gain for emerging adolescents. During this period of maturation, youth experience growing autonomy related to food choice and spend more time out of their home, but are not yet able to drive or stray far from home. ${ }^{38}$ Food choices in their neighborhood are thus likely to consist of a major portion of their discretionary food intake. Adolescents may also rely on unhealthy food retail outlets owing to taste preference for high-fat foods, convenience, and low cost. ${ }^{39}$ Although neighborhoods characterized by food retail shops may also include access to potentially healthy foods available at supermarkets, local grocery stores often have a poor assortment of fresh produce and low-fat options and charge higher prices than the large, chain grocery stores in suburban areas. ${ }^{40,41}$

Neighborhood physical disorder was also found to contribute to development of obesity during emerging adolescence. Although living in a neighborhood with highway overpasses, graffiti, and litter is associated with poverty, we also accounted for household income and census tract SES, and found that the effect of neighborhood physical disorder on increased risk for obesity remained. Garbage and traffic on local streets and graffiti on local buildings may discourage physical activity by increasing perceived danger in public places and reducing a sense of neighborhood social cohesion that may attract outdoor play. ${ }^{42}$ Neighborhood disorder may also increase the risk for obesity by elevating levels of psychological distress, which then leads to chronic activation of the physiologic stress response and increased food energy intake. ${ }^{43,44}$

Neither the neighborhood walkability scale nor the recreation scale was related to obesity risk in our study. Although these neighborhood characteristics 
are presumed to reduce obesity risk owing to increased physical activity or time spent outdoors, a more walkable neighborhood may not promote healthy behaviors if the streets and sidewalks are characterized by physical disorder (as described above). Additionally, although there is evidence that the presence of recreation equipment and parks promotes physical activity, it is possible that the school environment plays a larger role than the home environment in providing recreational opportunities for youth through physical education classes, school sports teams, and training facilities.22,45 Finally, the neighborhood walkability and recreation scales may be less influential for females compared with males. Previous research suggests that girls spend more of their leisure time indoors than boys, and are less likely to engage in outdoor play or use public resources in the neighborhood, 46,47 which may be tied to gender socialization or maturational status (eg, girls feeling discomfort or embarrassment related to puberty, which may deter active, outdoor play) $.48,49$

Our findings that the presence of food and service retailers and physical disorder in the neighborhood are associated with increased probability of subsequent obesity are striking. However, as CYGNET Study participants were members of KPNC at birth and at time of recruitment, they likely represent a more stable population than the general Bay Area populace. It is not clear how residential stability itself is associated with risk for obesity. As study participants were from families who had health insurance and access to health care, they also represent a somewhat selective population. However, KPNC membership is generally representative of the San Francisco Bay area, as approximately $30 \%$ of all Bay Area residents receive health care coverage from KPNC. Its membership differs from the rest of the population primarily by having lower percentages of members at the low- and high-income extremes, ${ }^{50}$ and the overall income distribution of this sample reflects the high cost of living in the Bay Area. Although those who have health care coverage may have differing rates of obesity than the general population, it seems unlikely that this would influence the association of neighborhood characteristics with risk for subsequent obesity.

Parents play an important role in deciding where the girls live, within their economic means, choosing neighborhoods based on reputation, schools, and amenities. We did not account for parents' or caregivers' perceptions of neighborhood safety or other attitudes or practices that may influence girls' risk for obesity. Therefore, future studies should measure parental factors that may influence both neighborhood selection and their daughters' eating and exercise behaviors. Future research could also incorporate parents' and girls' perceptions of the neighborhood and the resources they use close to home to deepen understanding of how neighborhood characteristics influence obesity risk.

Neighborhood characteristics were observed at only 1 time point (baseline). We therefore do not have data on neighborhood changes over time. To investigate this limitation, analyses were repeated on a random subset (10\%) of girls who did not change residences between the first 2 years of the study, to ascertain how much neighborhoods change from year to year. Other than variables where there would be day-to-day variability (eg, trash), other variables (eg, playgrounds, food stores, other retail establishments) did not change from one year to the next.

Although the above considerations suggest caution in interpreting study results, this study has considerable strengths. We used direct observations to characterize the neighborhood environment. BMl and pubertal status were collected through standardized clinical measures on a repeat basis. This enabled analysis using a longitudinal design to measure the influence of neighborhood factors on risk for progression to obesity across 4 years of follow-up.

\section{CONCLUSIONS}

In this prospective study, we found that girls who live in neighborhoods with increased access to food and service retailers and more physical disorder had a higher likelihood of becoming obese during the developmental transition from childhood to adolescence. These findings have important implications for future research, practice, and policy on childhood obesity, highlighting the need to consider neighborhood factors in youths' most proximal residential environments. Evaluating children's neighborhood characteristics within the health care setting would give pediatricians and other clinicians important, contextual knowledge about environmental influences on health that can be addressed directly in devising health plans. For example, youth who live in neighborhoods characterized by physical disorder could plan to spend extra time at school or another supervised setting, where they may be more inclined to play outdoors. Or health coaches can work with families to seek out alternative food options in areas where tempting and convenient unhealthy options are prevalent. Overall, clinicians can provide better guidance with an understanding of the contextual forces at play. Therefore, future efforts to reduce childhood obesity must address not only individual-level behaviors and family-level practices, but also consider design and planning characteristics of environments that may promote or threaten healthy development. 


\section{REFERENCES}

1. Ogden $\mathrm{CL}$, Carroll MD, Curtin LR, Lamb MM, Flegal KM. Prevalence of high body mass index in US children and adolescents, 20072008. JAMA. 2010;303(3):242-249

2. Ogden $\mathrm{CL}$, Carroll MD, Flegal KM. High body mass index for age among US children and adolescents, 2003-2006. JAMA. 2008;299 (20):2401-2405

3. Singh GK, Kogan MD, van Dyck PC. Changes in state-specific childhood obesity and overweight prevalence in the United States from 2003 to 2007. Arch Pediatr Adolesc Med. 2010;164(7):598-607

4. Ogden CL. Statistics NCfH. Prevalence of Obesity in the United States, 2009-2010. US Department of Health and Human Services, Centers for Disease Control and Prevention, National Center for Health Statistics; 2012

5. Frederick CB, Snellman K, Putnam RD. Increasing socioeconomic disparities in adolescent obesity. Proc Natl Acad Sci USA. 2014;111(4):1338-1342

6. Miech RA, Kumanyika SK, Stettler N, Link BG, Phelan JC, Chang VW. Trends in the association of poverty with overweight among US adolescents, 1971-2004. JAMA. 2006;295(20):2385-2393

7. Singh GK, Kogan MD, Van Dyck PC, Siahpush M. Racial/ethnic, socioeconomic, and behavioral determinants of childhood and adolescent obesity in the United States: analyzing independent and joint associations. Ann Epidemiol. 2008;18(9):682695

8. Grafova IB. Overweight children: assessing the contribution of the built environment. Prev Med. 2008;47(3):304-308

9. Hawkins SS, Pearce A, Cole TJ, et al; MilIennium Cohort Study Child Health Group. Perceived and objective measures of the neighbourhood environment and overweight in preschool children and their mothers. Int J Pediatr Obes. 2009;4(3):183192

10. Bacha JM, Appugliese D, Coleman S, et al. Maternal perception of neighborhood safety as a predictor of child weight status: The moderating effect of gender and assessment of potential mediators. Int $J$ Pediatr Obes. 2010;5(1):72-79

11. Cecil-Karb R, Grogan-Kaylor A. Childhood body mass index in community context: neighborhood safety, television viewing, and growth trajectories of BMI. Health Soc Work. 2009;34(3):169-177

12. Gordon-Larsen P, Nelson MC, Page P, Popkin BM. Inequality in the built environment underlies key health disparities in physical activity and obesity. Pediatrics. 2006;117(2): 417-424

13. Galvez MP, Hong L, Choi E, Liao L, Godbold J, Brenner B. Childhood obesity and neighborhood food-store availability in an innercity community. Acad Pediatr. 2009;9(5): 339-343

14. Jennings A, Welch A, Jones AP, et al. Local food outlets, weight status, and dietary intake: associations in children aged 9-10 years. Am J Prev Med. 2011;40(4):405-410

15. Saelens BE, Sallis JF, Frank LD, et al. Obesogenic neighborhood environments, child and parent obesity: the Neighborhood Impact on Kids study. Am J Prev Med. 2012;42 (5): e57-e64

16. Oreskovic NM, Winickoff JP, Kuhlthau KA, Romm D, Perrin JM. Obesity and the built environment among Massachusetts children. Clin Pediatr (Phila). 2009;48(9):904912

17. Scott MM, Dubowitz T, Cohen DA. Regional differences in walking frequency and BMI: what role does the built environment play for Blacks and Whites? Health Place. 2009; 15(3):882-887

18. Feng J, Glass TA, Curriero FC, Stewart WF, Schwartz BS. The built environment and obesity: a systematic review of the epidemiologic evidence. Health Place. 2010;16(2): 175-190

19. Archibald A, Graber J, Brooks-Gunn J. Pubertal processes and physiological growth in adolescence. In: Adams G, Berzonsky M, eds. Blackwell Handbook of Adolescence. Malden, MA: Blackwell; 2003:24-47

20. Barnes HV. Physical growth and development during puberty. Med Clin North Am. 1975;59(6):1305-1317

21. Daniels SR, Arnett DK, Eckel RH, et al. Overweight in children and adolescents: pathophysiology, consequences, prevention, and treatment. Circulation. 2005;111(15): 1999-2012

22. Dietz WH, Gortmaker SL. Preventing obesity in children and adolescents. Annu Rev Public Health. 2001;22(1):337-353

23. Alberga AS, Sigal RJ, Goldfield G, Prud'homme D, Kenny GP. Overweight and obese teenagers: why is adolescence a critical period? Pediatr Obes. 2012;7(4): 261-273

24. Hiatt RA, Haslam SZ, Osuch J; Breast Cancer and the Environment Research Centers. The breast cancer and the environment research centers: transdisciplinary research on the role of the environment in breast cancer etiology. Environ Health Perspect. 2009;117(12):1814-1822
25. Biro FM, Galvez MP, Greenspan LC, et al. Pubertal assessment method and baseline characteristics in a mixed longitudinal study of girls. Pediatrics. 2010;126(3). Available at: www.pediatrics.org/cgi/content/full/126/ 3/e583

26. Brownson RC, Hoehner CM, Brennan LK, Cook RA, Elliott MB, McMullen KM. Reliability of 2 instruments for auditing the environment for physical activity. J Phys Act Health. 2004;1:191-208

27. Leung CW, Gregorich SE, Laraia BA, Kushi $\mathrm{LH}$, Yen IH. Measuring the neighborhood environment: associations with young girls' energy intake and expenditure in a crosssectional study. Int J Behav Nutr Phys Act. 2010;7:52

28. Messer LC, Laraia BA, Kaufman JS, et al. The development of a standardized neighborhood deprivation index. J Urban Health. 2006;83(6):1041-1062

29. Morris NM, Udry JR. Validation of a selfadministered instrument to assess stage of adolescent development. $J$ Youth Adolesc. 1980;9(3):271-280

30. Udry JR, Cliquet RL. A cross-cultural examination of the relationship between ages at menarche, marriage, and first birth. Demography. 1982;19(1):53-63

31. Whitaker RC, Wright JA, Pepe MS, Seidel KD, Dietz WH. Predicting obesity in young adulthood from childhood and parental obesity. N Engl J Med. 1997;337(13):869-873

32. Serdula MK, Ivery D, Coates RJ, Freedman DS, Williamson DF, Byers T. Do obese children become obese adults? A review of the literature. Prev Med. 1993;22(2):167-177

33. Must A, Jacques PF, Dallal GE, Bajema CJ, Dietz WH. Long-term morbidity and mortality of overweight adolescents. A followup of the Harvard Growth Study of 1922 to 1935. N Engl J Med. 1992;327(19):13501355

34. Taveras EM, Berkey CS, Rifas-Shiman SL, et al. Association of consumption of fried food away from home with body mass index and diet quality in older children and adolescents. Pediatrics. 2005;116(4). Available at: www.pediatrics.org/cgi/content/ full/116/4/e518

35. Bowman SA, Gortmaker SL, Ebbeling CB, Pereira MA, Ludwig DS. Effects of fast-food consumption on energy intake and diet quality among children in a national household survey. Pediatrics. 2004;113(1 pt 1):112-118

36. Prentice AM, Jebb SA. Fast foods, energy density and obesity: a possible mechanistic link. Obes Rev. 2003;4(4):187-194 
37. Rosenheck R. Fast food consumption and increased caloric intake: a systematic review of a trajectory towards weight gain and obesity risk. Obes Rev. 2008;9(6):535547

38. Bassett R, Chapman GE, Beagan BL. Autonomy and control: the co-construction of adolescent food choice. Appetite. 2008;50(23):325-332

39. Neumark-Sztainer D, Story M, Perry C, Casey MA. Factors influencing food choices of adolescents: findings from focus-group discussions with adolescents. J Am Diet Assoc. 1999;99(8):929-937

40. Chung C, Myers SL. Do the poor pay more for food? An analysis of grocery store availability and food price disparities. J Consum Aff. 1999;33(2):276-296

41. Cummins S, Macintyre S. Food environments and obesity-neighbourhood or nation? Int J Epidemiol. 2006;35(1):100104
42. Carver A, Timperio A, Crawford D. Playing it safe: the influence of neighbourhood safety on children's physical activity. A review. Health Place. 2008;14(2):217-227

43. Burdette AM, Hill TD. An examination of processes linking perceived neighborhood disorder and obesity. Soc Sci Med. 2008;67 (1):38-46

44. Steptoe A, Feldman PJ. Neighborhood problems as sources of chronic stress: development of a measure of neighborhood problems, and associations with socioeconomic status and health. Ann Behav Med. 2001;23(3):177-185

45. Ferreira I, van der Horst K, Wendel-Vos W, Kremers S, van Lenthe FJ, Brug J. Environmental correlates of physical activity in youth - a review and update. Obes Rev. 2007;8(2):129-154

46. Gordon-Larsen P, McMurray RG, Popkin BM. Determinants of adolescent physical activity and inactivity patterns. Pediatrics. 2000;
105(6). Available at: www.pediatrics.org/ cgi/content/full/105/6/E83

47. Maccoby EE. The Two Sexes: Growing Up Apart, Coming Together. Cambridge, MA Harvard University Press; 1998

48. Thorne B. Gender Play: Girls and Boys in School. Piscataway Township, NJ: Rutgers University Press; 1993

49. Davison KK, Werder JL, Trost SG, Baker BL, Birch LL. Why are early maturing girls less active? Links between pubertal development, psychological well-being, and physical activity among girls at ages 11 and 13. Soc Sci Med. 2007;64(12):2391-2404

50. Gordon NP. Similarity of the adult Kaiser Permanente Membership in Northern California to the insured and general population in Northern California: Statistics from the 2007 California Health Interview Survey. Internal Division of Research report. Available at: www.dor.kaiser.org/external/ chis_non_kp_2007/ Published 2012

(Continued from first page)

Address correspondence to Lindsay T. Hoyt, PhD, Center for Health and Community, University of California at San Francisco, 3333 California St, Suite 465, San Francisco, CA 94118. E-mail: hoytl@chc.ucsf.edu

PEDIATRICS (ISSN Numbers: Print, 0031-4005; Online, 1098-4275).

Copyright (C) 2014 by the American Academy of Pediatrics

FINANCIAL DISCLOSURE: The authors have indicated they have no financial relationships relevant to this article to disclose.

FUNDING: The CYGNET study was made possible by the Breast Cancer and the Environment Research Program award numbers U01ES012801, U01ES019435, and U01ES019457 from the National Institute of Environmental Health Sciences and the National Cancer Institute, and UL1RR024131 from the National Center for Research Resources. Additional funding for the neighborhood sub-study came from the California Breast Cancer Research Program (grants 12IB-0013 and 14NB0173) and seed funding from the Robert Wood Johnson Foundation Health and Society Scholars program. Lindsay Hoyt, Nancy Adler, and Barbara Laraia were supported by funding from the Robert Wood Johnson Foundation Health and Society Scholars program.

POTENTIAL CONFLICT OF INTEREST: The authors have indicated they have no potential conflicts of interest to disclose. 